\title{
Mulligan bent leg raise tekniği ve kinesiotape'nin hamstring kası kısalığına anlık etkilerinin karşılaştırılması
}

Tahir KESKINN ${ }^{1}$, Ferdi BAȘKURT ${ }^{2}$, Zeliha BAȘKURT ${ }^{2}$, Tuba İNCE PARPUCU ${ }^{3}$

\begin{abstract}
$\ddot{\mathbf{O} z}$
Calıșmamızın amacı hamstring kası kısalığına mulligan bent leg raise (BLR) tekniği ve kinezyoteyp (KT) uygulamasının anlık ve 24 saatlik etkisini ve belirlemektir. Çalı̧̧maya hamstring kısalığı olan 54 kişi katılmış ve randomize olarak iki gruba ayrılmıştır. (grup 1= BLR grubu, grup 2=KT grubu). Hamstring kısalığını değerlendirmek amacıyla otur-uzan testi yapılmış ve aktif diz ekstensiyon derecesi halo gonyometre ile ölçülmüştür. Değerlendirmeler uygulamadan önce, 30 dakika sonra ve 24 saat sonra yapılmıştır. Değerlendirmelerin analizi sonucunda her iki grupta da otur- uzan testi ve aktif diz ekstensiyon derecesinde anlamlı artış gözlenmiştir $(\mathrm{p}=0,000)$. Gruplar kendi aralarında karşılaştırıldığında, otur- uzan testinde 30 dakika sonra yapılan ölçümlerde BLR tekniğinin $(\mathrm{p}=0,010) ; 24$ saat sonra yapılan ölçümlerde ise KT uygulamasının $(0.032)$ etkinliğinin istatistiksel olarak daha anlamlı olduğu bulunmuştur. Aktif diz ekstensiyon derecesinde ise 30 dakika sonra yapılan ölçümlerde BLR tekniğinin $(0,00)$ etkinliği istatistiksel olarak daha anlamlı bulunmuştur. Diğer test parametrelerinde istatistiksel olarak anlamlı bir farklılık bulunmamıştır. Hem KT uygulaması hem de BLR tekniği hamstring kası esnekliğinin artırılmasında etkilidir. Hamstring kısalığına yönelik anlık etki istendiğinde BLR tekniğinin, daha uzun süreli etki istendiğinde ise KT uygulamasının daha etkili olduğu belirlenmiştir.
\end{abstract}

Yayın Bilgisi

Anahtar Kelimeler: Esneklik, hamstring kası, mulligan bent leg raise tekniği, kinesiotape, aktif diz ekstensiyon testi

\section{The comparison of immediate effects of Mulligan's bent leg raise technique and kinesiotape on hamstring tightness}

Tahir KESKINN ${ }^{1}$, Ferdi BAŞKURT ${ }^{2}$, Zeliha BAŞKURT ${ }^{2}$, Tuba INCE PARPUCU ${ }^{3}$

\begin{abstract}
The aim of this study is to investigate the immediate and 24- hours effects of Mulligan's bent leg raise (BLR) technique and kinesio tape (KT) on hamstring tightness. 54 subjects with hamstring tightness participated in the study and and the subjects were randomly divided into two groups (group 1= BLR, group $2=\mathrm{KT}$ group). To assess hamstring tightness, sit and reach test was performed and the active knee extension grade was measured with a halo goniometer. Measurements were taken pre- intervention, 30 minutes after intervention and 24 hours after intervention. After the analyses of the measurements, statistically significant increase were found in both groups on active knee extension and sit and reach test $(p=0,000)$. In comparison of the groups; after $30 \mathrm{~min}$. measurements BLR results showed statistically significant improvement than KT $(\mathrm{p}=0,01)$, however after 24 hours measurements; statistically significant improvement was detected in KT than BLR $(p=0,032)$ on sit and reach test. On active knee extension test BLR showed greater improvement than KT at measurements taken after 30 minutes $(p=0,00)$. There were no statistically significant differences on the other test parameters. Both KT application and BLR technique are effective on increasing hamstring muscle's flexibility. It has been determined that the BLR technique is more effective in the need of immediate effect on hamstring shortness and the $\mathrm{KT}$ application is more effective when the longer effect is required.
\end{abstract}

Gönderi Tarihi:19.02.2018

Kabul Tarihi:12.06.2018

Online Yayın Tarihi:30.09.2018

DOI: $10.26453 /$ otjhs.396718

Sorumlu Yazar

Tahir KESKIN

Keywords: Flexibility, hamstring muscle, mulligan's bent leg raise technique, kinesiotape, active knee extension test

\footnotetext{
${ }^{1}$ Arş. Gör., Süleyman Demirel Üniversitesi Sağlık Bilimleri Fakültesi Fizyoterapi ve Rehabilitaston Bölümü, Isparta, Türkiye ${ }^{2}$ Doç. Dr., Süleyman Demirel Üniversitesi Sağlık Bilimleri Fakültesi Fizyoterapi ve Rehabilitaston Bölümü, Isparta, Türkiye

${ }^{3}$ Yrd. Doç. Dr., Süleyman Demirel Üniversitesi Sağlık Bilimleri Fakültesi Fizyoterapi ve Rehabilitaston Bölümü, Isparta, Türkiye

* Bu çalışma I. Uluslararası Sağlık Bilimleri Kongresi’nde sözel bildiri olarak sunulmuştur.
} 


\section{GíRIŞ}

Esneklik, kısıtlı olmayan bir hareket aralığında tek veya bir dizi eklem düzleminde kasın hareket etme yeteneğidir. ${ }^{1}$ Kas esnekliği, kasın fonksiyonelliğinin önemli bir unsurudur ve kasın biyomekanik fonksiyonunu sağlamak için çok önemli bir yere sahiptir. Literatürde esnekliğin faydaları arasında; atletik performans1 arttırması, yaralanma riskini azaltması, egzersiz sonrası ağrıyı önlemesi veya azaltması ve koordinasyonu geliştirmesi sayılabilir. Ayrıca yaralanmanın önlenmesi ve rehabilitasyonu için önemli bir bileşendir. Sınırlı bir esneklik, kişide çeşitli kas-iskelet sistemi overuse yaralanmalarına yatkınlığa neden olur ve fonksiyonelliği önemli derecede etkiler. ${ }^{2,3}$

Esneklik her bir kas için farklıdır. Bu farklılık kas üzerine verilen streslere kasın göstereceği adaptasyona bağlıdır. Azalmış esneklik genellikle hızlı kasılan ve iki eklem kat eden kaslarda görülür. Hamstring kasları bunun tipik bir örneğidir. ${ }^{4}$ Normal günlük aktivitelerde hamstring kaslarının fizyolojik amplitüdlerinin nadiren tamamı gerçekleşir. $\mathrm{Bu}$ nedenle hamsrting kasları kısalma eğilimi gösteren kas gruplarındandır. Hamstring kısalığ semptomatik hem de asemptomatik kişilerde, dünya genelinde hemen hemen tüm popülasyonlarda görülmektedir. Hamstring kısalığının sebepleri arasında genetik faktörler, akut veya kronik yaralanmaya kasın göstereceği adaptasyon, uzun süre oturur pozisyonda durmak vs. sayılabilir. Bazı araştırmalar azalmış hamstring esnekliğinin patella tendinopatisine, patellofemoral ağriya, hamstring strainine ve eksantrik egzersiz sonrası kas hasarına neden olabileceğini belirtmişlerdir. $^{5} \mathrm{Bu}$ nedenle hamstring kaslarının esnekliğinin korunması gerekir. Esnek hamstringler akut ve kronik kasiskelet yaralanmalarını, bel ağrısını, postür deviasyonlarını, yürüyüş limitasyonlarını ve düşme riskini önleyebilir.

Hamstring esnekliğini arttırmak için genellikle germe egzersizleri yapılır. ${ }^{2}$ Ayrıca hamstring esnekliğini arttırmaya yönelik farklı yöntemler de vardır. Bu yöntemler biri Mulligan Bent Leg Raise (BLR) tekniğidir. BLR doğasında ağrısız bir germe yöntemidir. ${ }^{5} \mathrm{Bu}$ teknik, hamstring kasının değiştirilmiş aktivasyonunu düzeltmek için tasarlanmıştır. Hamstring kaslarının esnekliğini arttırarak aktif diz ekstansiyonu ve kalça fleksiyonunu arttırmak amaçlanır. Uygulama, kalça fleksiyonu yönünde spesifik bir doğrultuda hamstring kasının nazikçe gerilmesi prensibine dayanır, ağrısız bir tedavi yöntemidir. ${ }^{5}$ Yapılan çalışmalar BLR tekniğinin hamstring fleksibilitesini arttırdığını ve ağrıyı azalttı̆̆ını göstermektedir., 6, 7

Kinesiotape (KT) uygulaması vücudun doğal iyileşme sürecini kolaylaştırmak için tasarlanmış, kas ve eklem hareketlerini destekleyen ve ağrıyı azaltan bir bantlama tekniğidir. $^{4}$ KT uygulaması cilt ile kaslar arasındaki boşluğu artırmak için kıvrımlar oluşturur ve teorik olarak lenfatik drenajı arttırır. Yapılan çalışmalar, KT'nin kuvvet, 
eklem pozisyon hissi, kas performans1, normal eklem hareketi (NEH), propriosepsion ve lenfödem alanlarında olumlu sonuçlar verdiğini, aynı zamanda alt gövde ve servikal NEH'i arttırdığını göstermiştir. ${ }^{8,} 9,10 \mathrm{KT}$ ' nin NEH' e etkisi, bantlanmış bölgenin kan dolaşımını arttırması ile açıklanır ve bu etki miyofasiyal dokuda fizyolojik değişikler oluşturur. Başka bir teoriye göre, bantlanmış alandaki kutaneöz mekanoreseptörler stimüle edildiğinden $\mathrm{NEH}$ artmaktadır. $^{4}$

Literatüre bakıldığında BLR tekniği ve KT uygulamasının hamstring esnekliğini arttırmaya yönelik olumlu sonuçlar verdiği görülmektedir fakat hamstring kısalığına yönelik KT uygulaması ve BLR tekniğinin anlık etkilerini karşılaştıran bir çalışmaya rastlanılmamıştır. $\mathrm{Bu}$ nedenle çalışmamızın amacı BLR ve KT uygulamalarının hamstring fleksibilitesi üzerine anlık etkilerini karşılaştırmaktır.

\section{MATERYAL VE METOT}

BLR ve KT yöntemlerinin hamstring fleksibilitesi üzerine anlık etkilerinin karşılaştırılması amacıyla yaptığımız çalışmamıza; yaşları 21 ile 27 arasında değişen onamları alınmış 25 kız, 29 erkek üniversite öğrencisi gönüllülük esasıyla çalıșmaya dâhil edilmiştir. Çalışma öncesinde çalışmaya katılan bireylere çalışmanın amaç ve prosedürleri açıklanmış ve çalışma Helsinki Deklerasyonu' na uygun bir şekilde yürütülmüştür. Aktif diz

ekstansiyonunun en az 15 derece limitli olması dâhil edilme kriterini oluşturmaktadır. Son iki yıl içerisinde hamstring yaralanması geçiren, son iki ay içersinde bel ağrısı yaşayan, alt extremite veya lumbal bölgede nörolojik problem yaşayan kişiler çalışmanın dışında tutulmuştur. Dâhil edilme kriterlerine uygun bireyler basit randomizasyon yöntemiyle iki gruba ayrılmış, 1. Gruba Mulligan BLR tekniği, 2. Gruba KT uygulanmıştır. Ölçümler; müdahale öncesinde, 30 dakika sonra ve 24 saat sonra aynı fizyoterapist tarafindan yapılmıştır. Kinesiotape ve mulligan uygulamaları alanında tecrübeli ve uygulama sertifikaları olan fizyoterapistler tarafindan yürütülmüsştür.

\section{Mulligan bent leg raise tekniği}

Mulligan bent leg raise tekniği izometrik kasılmayı takiben, hamstring kasına spesifik yönlerde yapılan nazik germeleri içerir, hamsting esnekliğini ve aktif diz ekstensiyon normal eklem hareketini arttırmak hedeflenir. Denek sırtüstü yatış pozisyonundadır. Fizyoterapist uygulama yapılacak dizi popliteal fossa omuza tam temas edecek şekilde omzuna yerleştirmiştir. $\mathrm{Bu}$ pozisyonda denekten fizyoterapisti diziyle itmesi, ardından gevșemesi istenmiștir. Fizyoterapist traksiyonla birlikte hastanın dizini ağrısız aralıkta kalça fleksiyonu yönünde mümkün oldukça ittirmiştir. Hareketin son noktasinda bu pozisyon 5saniye kadar korunmuş ardından ekstremite nörtal pozisyona alınmıştır. BLR uygulaması 3 defa tekrarlanmıştır. 


\section{Kinesiotape uygulamast}

Denek ayakta duruş pozisyonundadır. Yeterli kalça fleksiyonu elde edebilmek için denek gövde fleksiyonu yapmıştır. Fizyoterapist ilk olarak fibula başından tuberositas 1schi' ye kadar olan mesafeyi bant ile ölçmüş ve bandı \%20 oranında gererek hamstring kaslarının medial kenarına, distalden proksimale doğru (distalden proksimale uygulanan bant kas fonksiyonunu inhibe eder) yapıştırmıştır. Ardından aynı uygulamayı tibianın medial kondili ve tuberositas 1schi arasında I band1 şeklinde yapmıştır.

\section{Aktif diz ekstensiyon testi}

Aktif diz ekstensiyon testi hamstring kaslarının esnekliğini değerlendirmek için kullanılan objektif bir testtir. Sağlıklı yetişkinlerde geçerlilik-güvenirliliği kanıtlanmıştır. ${ }^{11}$ Çalışmamızda aktif diz ekstansiyon derecesi halo dijital gonyometre ile ölçülmüştür. Denek sırtüstü yatış pozisyonundadır. Fizyoterapist deneğin kalça ve dizini $90^{\circ}$ fleksiyona alıp (açı gonyometre ile doğrulanmıştır) kalçanın $90^{\circ}$, lik fleksiyon açısının bozulmamamsı için bir eliyle deneğin dizini stabilize etmiştir. Ardından denekten dizini ekstansiyona alması istenmiş ve ekstansiyon açısı halo dijital gonyometre ile ölçülüp kaydedilmiştir.

\section{Back-saver otur-uzan testi}

Back-saver otur-uzan testi; otur uzan testi ile aynıdır, tek farkı testin tek taraflı olarak yapılmasıdır. ${ }^{1}$ Test, otur-uzan test kutusu kullanılarak uygulanmıştır. Katılımcılar düz zeminde yere oturmuş ve ölçüm yapılacak ayak tabanı düz bir şekilde test sehpasına yaslanmıştır. Diğer ayak tabanı ölçüm yapılacak dizin 7-10 cm yanına alınarak ve yerle temasının korunması istenmiştir. ${ }^{12}$ Katılımcılardan avuç içi aşağıya bakacak ve eller üst üste gelecek şekilde, gövdesiyle ölçüm çizgisinde doğru mümkün oldukça ileriye uzanmaları, eliyle uzanabildiği en son noktada bir iki saniye beklemeleri istenmiş ve üç deneme yaptıktan sonra en iyi derece kayıt edilmiştir.

\section{İstatistiksel Analiz}

Katılımcilardan elde edilen tüm verilerin istatistiksel analizleri IBM SPSS Statistics versiyon 20.0 programı ile yapılmıştır. Uygulamaların anlamlılığı Friedman testi ile belirlenmiştir. Grup içi değerlendirmeler arasındaki farklar Wilcoxon testi ile, her iki grup arasındaki fark ise Mann- Whitney U testi ile analiz edilmiştir.

\section{BULGULAR}

Katılımcıların demografik özellikleri Tablo 1'de gösterilmiştir.

Yapılan değerlendirmelerin analizi sonucunda; Mulligan BLR tekniği ve Kinesiotape uygulaması sonrası $30 \mathrm{dk}$ ve 24 saat sonraki ölçümlerde otur- uzan testi ve aktif diz ekstansiyon derecesinde istatistiksel olarak 
anlamlı bir farklılığı $\quad(p=0,00) \quad$ olduğu görülmüştür (Tablo 2).

Grup içi değerlendirmelerde; her iki test parametresinde 30 dakika ve 24 sonra yapılan ölçümlerde uygulama öncesi değerlere göre anlamlı bir artış gözlenmiştir $(\mathrm{p}=0,00) .30$ dakika ve 24 sonra yapılan ölçümler arasında ise anlamlı bir fark gözlenmemiştir ( $p>0,05)$.

Gruplar kendi aralarında karşılaştırıldığında ise, 30 dakika sonra yapılan ölçümlerde; hem oturuzan testinde $(p=0,010)$ hem de aktif diz ekstansiyon derecesinde $(p=0,00) \quad$ BLR tekniğinin kinesiotape uygulamasına göre etkinliğinin istatistiksel olarak daha anlamlı olduğu bulunmuştur. 24 saat sonraki ve 30 dakika sonraki ölçümlerin fark değerlerinin analizinde KT uygulaması BLR tekniğine göre istatistiksel olarak anlamlı sonuçlar vermiştir $(p=0,032)$. Diğer ölçümlerde gruplar arasında anlamlı bir farklılık bulunmamıştır (Tablo 3).

\section{TARTIŞMA VE SONUÇ}

Hamstring kısalığına Mulligan Bent Leg Raise tekniği ve Kinesiotape' nin anlık etkilerinin incelenmesi amacıyla yaptığımız çalışmamızın sonuçlarına göre; hamstring kası esnekliğinin arttırılmasında hem KT uygulaması hem de BLR tekniği etkilidir. Her iki yöntem de 24 saat boyunca etkinliğini korumuştur. Otur-uzan testinde ve aktif diz ekstensiyon değerlerinde 30 dakika sonra yapılan ölçümlerde BLR tekniğinin KT uygulamasına göre istatistiksel olarak daha anlamlı olduğu bulunmuştur. Hamstring fleksibilitesini arttırmaya yönelik anlık etki elde etmek istendiğinde BLR tekniği her iki değerlendirme parametresinde KT uygulamasından daha etkilidir. İki uygulama arasındaki bu farkın; Mulligan tekniklerinin anlık etkisiyle bilinmesinden, KT uygulamasının ise zamanla etkinleşmesinden kaynaklandığı düşünülmektedir.

Literatüre bakıldığında hamstring kasına KT uygulamasının daha çok akut etkisini araştıran çalışmalara rastlanmıştır. ${ }^{4,}{ }^{13},{ }^{14}$ Farquharson ve ark. KT uygulamasının zamansal paternini inceledikleri çalışmada KT uygulanan bireylerin uygulamadan hemen sonra, 10 dakika ve 30 dakika sonra aktif diz ekstansiyon dereceleri değerlendirilmiş ve en fazla artışın 24. dakikada olduğunu belirtmişlerdir. ${ }^{15}$ Lumbroso ve ark. hamstring kasına yapılan KT uygulamasının akut dönemde (uygulamadan 15 dakika sonra) düz bacak kaldırma derecesinde anlamlı artışa neden olduğunu, 48 saat sonraki değerlerin ise anlamlı olmadığını belirtmiştir. $^{16}$ Bizim çalışmamızda ise KT uygulamasının hem 30 dakikada hem de 24 saatte etkin olduğu belirlenmiștir. $\mathrm{Bu}$ veriler $\mathrm{KT}$ uygulamasının etkinliğinin zamanla değişimiyle ilgili daha fazla çalışma yapılması gerektiğini göstermektedir.

Ayala ve ark. hamstring kısalığı olan sağlıklı gençlerde yapmış oldukları çalışmada ${ }^{17}$; haftada 3 defa ve 12 hafta boyunca yapılan statik germe egzersizinin hamstring esnekliğini 4 haftada 
yaklaşık 8 derece arttırdığını göstermiştir. Bizim çalışmamızda ise anlık etki olarak özellikle BLR grubunda yaklaşık 9 derecelik bir artış gözlenmiştir. Hamstring esnekliğindeki bu artış statik germe ile yaklaşık 4 haftada elde edilmektedir. $\mathrm{Bu}$ da $\mathrm{BLR}$ tekniğinin anlık etkisinin önemini göstermektedir. BLR tekniğinin anlık etkisinin mekanizması tam olarak bilinmemektedir. Bu teknikte kas ağrısız bir hareket aralığında yavaşça uzatılır ve kasın tolere edilen maximum uzunluğunda bu pozisyon korunur. ${ }^{7}$ BLR tekniğinin anlik etkisinin bundan kaynaklandığı düşünülmektedir.

Dixon ve ark. düz bacak kaldırma (DBK) hareketinde gerçek bir değişim meydana geldiğini belirtmek için 6 dereceden daha fazla bir artış olması gerektiğini öne sürmüştür. ${ }^{18}$ Hamstring esnekliği üzerine yapılan çalışmalarda DBK 'daki artış 3 ile 13 derece arasında değişmektedir. ${ }^{4,6,7}$ Bizim çalışmamızda ise aktif diz ekstensiyonundaki artış uygulamadan 30 dakika sonra BLR grubunda yaklaşık 8, KT grubunda 5 derece; 24 saat sonra ise BLR grubunda yaklaşık 7, KT grubunda 6 derecedir ve her iki uygulamada da Dixon 'un belirttiği değere ulaşılmıştır. Uygulamalar arasındaki bu farklılığın; örneklem büyüklüğü, uygulamanın belirli bir patolojisi olan gruplarda (bel ağrısı vs.) yapılmış olması ve uygulanan yöntemle alakalı olduğu düşünülmektedir.

Kase ve ark. ${ }^{19}$ proksimalden distale yapilan KT uygulamalarının kas fonksiyonunu fasilite ettiğini, distalden proksimale yapılan uygulamaların ise inhibe ettiğini belirtmiştir. Lumbroso ve ark. yaptığı çalışmada proksimaldistal yönlü uygulama yapmış ve bunun sebebini proksimal- distal yönlü uygulamanın daha sık kullanılması olarak göstermiştir. ${ }^{16}$ Literatüre bakıldığında hamstring kaslarına I ve Y şeklinde bantlar uygulanmıştır. Uygulama yönü ise genellikle proksimalden distaledir. $\mathrm{Bu}$ uygulamalarda ${ }^{4,13,16}$ DBK veya aktif diz ekstensiyonu 2 ile 10 derece arasında artış göstermiştir. Bizim çalışmamızda ise 6 derecelik bir artış saptanmıştır. Bu veriler KT' nin uygulama yönü ile ilgili fikir ayrılığ olduğunu göstermektedir ve KT’ nin uygulama yönü ile ilgili daha fazla çalışma yapılması gerektiğini göstermektedir.

Sportif aktiviteler sırasında hamstring kaslarının esnekliği çok önemlidir. Esnek hamstringler sportif aktiviteler sırasında meydana gelebilecek yaralanmaları önler. $\mathrm{Bu}$ nedenle özellikle esneklik gerektiren sportif aktiviteler öncesi hamstringlere yapılacak KT veya BLR uygulamaları değerlidir. Yapılan araştırmanın sonucuna göre her iki teknik de akut dönemde hamstring esnekliğini arttırmak için kullanılabilir.

Çalışmanın kısıtlılıklarından biri kontrol grubu olmamasıydı. Bu nedenle gruplar sadece kendi arasında karşılaştırıldı, karşılaştırma yapılırken kontrol grubu baz alınamadı. Çalışmanın bir diğer k1sitlılığ 1 ise; her iki uygulamanın 30 dakika ve 24 saatlik etkisine bakılabilmesiydi. 
Sonuç olarak, hamstring kası esnekliğinin arttırılmasında hem KT uygulaması hem de BLR tekniği etkilidir. Her iki uygulama da 24 saat boyunca etkinliğini korumuştur. Hamstring

\section{KAYNAKLAR}

1. Patni O, M Saravanan, Shaikh A, Juneja A, Shaikh N, Patel R. Effect of single bout of passive stretching and Mulligan's Bent Leg Raise (BLR) on Hamstring flexibility in young adults with asymptomatic bilateral Hamstring tightness. IOSR Journal of Dental and Medical Sciences. 2013; 9(3) : 13-17.

2. Hopper D, Deacon S, Das S, Jain A, Riddell D, Hall T, Briffa K. Dynamic soft tissue mobilisation increases hamstring flexibility in healthy male subjects. Br J Sports Med. 2005; 39: 594-598.

3. Khuman PR, Surbala L, Patel P, Chavda D. Immediate Effects of Single Session Post Isometric Relaxation Muscle Energy Technique Versus Mulligan's Bent Leg Raise. International Journal of Scientific Research. 2014; 3(9): 310-313.

4. Medeni ÖÇ, Baltacı G, Vayvay GD. Acute effect of kinesiotape muscle technique on hamstring flexibility and pain during stretching. Türk Fizyoterapi ve Rehabilitasyon Dergisi. 2015; 26(2): 73-77

5. Singh BK, Pattnaik M, Mohanty P. A Comparative Study of Mulligan Traction Straight Leg Raising and Dynamic Soft kısalığına yönelik anlık etki istendiğinde BLR tekniğinin, daha uzun süreli etki istendiğinde ise KT uygulamasının daha etkili olduğu belirlenmiştir.

Tissue Mobilization to Increase Hamstrings's Flexibility. 2016; 5; 4.

6. Hall T, Hardt S, Schafer A, Wallin 1. Mulligan bent leg raise technique-a preliminary randomized trial of immediate effects after a single intervention. Manual Therapy. 2006; 11: 130-135.

7. Phansopkar PA, Kage V. Efficacy of mulligan's two leg rotation and bent leg raise techniques in hamstring flexibility in subjects with acute non-specific low back pain: randomized clinical trial. International Journal of Physiotherapy and Research. 2014; 2(5): 733-41.

8. Özmen T, Güneş GY, Doğan H, Uçar I, Willems M. The effect of kinesio taping versus stretching techniques on muscle soreness, and flexibility during recovery from nordic hamstring exercise. Journal of Bodywork \& Movement Therapies. 2017; 21: $41-47$

9. Halseth T, McChesney JW, DeBeliso M, Vaughn R, Lien J. The effects of kinesiotape on proprioception at the ankle. J Sports Sci Med. 2004; 3 (1): 1-7.

10. Tsai HJ, Hung HC, Yang JL, Huang CS, Tsauo JY. Could Kinesio tape replace the 
bandage in decongestive lymphatic therapy for breast-cancer-related lymphedema? A pilot study. Support Care Cancer. 2009; 17(11): 1353-60.

11. Hamid MS, Mohamed Ali MR, Yusof A. Interrater and Intrarater Reliability of the Active Knee Extension (AKE) Test among Healthy Adults. J. Phys. Ther. Sci. 2013; 25: 957-961

12. Baltaci $\mathrm{G}$, Un $\mathrm{N}$, Tunay $\mathrm{V}$, Besler $\mathrm{A}$, Gerçeker S. Comparison of three different sit and reach tests for measurement of hamstring flexibility in female university students. $\mathrm{Br} \mathrm{J}$ Sports Med. 2003; 37: 59-61

13. Marban MR, Rodrıguez FE, Fernandez IL, Vega DM. The acute effect of kinesio taping on hamstring extensibility in university students. Journal of Physical Education and Sport. 2011; 11(2): 23-27

14. Chen CH, Tsun-Shun Huang TS, Chai HM, Jan MH, Lin JJ. Two Stretching Treatments for the Hamstrings: Proprioceptive Neuromuscular Facilitation Versus Kinesio Taping. Journal of Sport Rehabilitation. 2013; 22: 59-66
15. Farquharson C, Greig M. Temporal efficacy of kinesiology tape vs. traditional stretching methods on hamstring extensibility. The International Journal of Sports Physical Therapy. 2015; 10(1): 45-51.

16. Lumbroso D, Ziv E, Vered E, Kalichman L. The effect of kinesio tape application on hamstring and gastrocnemius muscles in healthy young adults. Journal of Bodywork \& Movement Therapies. 2014; 18: 130-138

17. Ayala F, Baranda P.S, Santonja F. Comparison of active stretching technique in males with normal and limited hamstring flexibility. Physical Therapy in Sport. 2013; 14(2): 98-104

18. Dixon JK, Keating JL. Variability in straight leg raise measurements: review. Physiotherapy. 2000; 86(7): 361-70.

19. Kase K, Wallis J, Kase T. Clinical Therapeutic Applications of the Kinesio Taping Method. Tokyo. Ken Ikai Co. Ltd. 2003. Hedrick A. Physiological responses to warm up. National Strength and Conditioning Journal. 1992;14(5):25-27. 
Tablo 1. Katılımcıların Demografik Özelliklerinin Dağılımı

\begin{tabular}{cccc} 
& Kinesiotape & Mulligan BLR & \\
& $\mathrm{n}=27$ & $\mathrm{n}=27$ & $\mathrm{p}^{*}$ \\
& mean $\pm \mathrm{SD}$ & mean $\pm \mathrm{SD}$ & \\
\hline Yaş & $22,85 \pm 1,45$ & $22,74 \pm 1,99$ &, 344 \\
Cinsiyet (k/e) & $10 / 17$ & $15 / 12$ &, 183 \\
Vücut kütle indeksi & $22,87 \pm 2,47$ & $22,09 \pm 3,01$ & \\
Dominant & $26 / 1$ & & \\
ekstremite(sağ/sol) & & $26 / 1$ & \\
\hline
\end{tabular}

$*=$ İstatistiksel anlamlılık $\mathrm{p}<0.005$ olarak belirlenmiştir. KT= Kinesiotape, BLR= Bent Leg Raise, $\mathrm{SD}=$ Standart Sapma, $\mathrm{k}=$ Kadın, $\mathrm{e}=$ Erkek,

Tablo-2: Uygulamaların etkinliğinin belirlenmesi

Grup
Sonra

\begin{tabular}{cccccc}
\hline $\begin{array}{c}\text { Aktif diz ekstensiyon } \\
\text { derecesi }\end{array}$ & KT & $32,1 \pm 11,9$ & $27,1 \pm 10,4$ & $25,8 \pm 9,8$ & 0,00 \\
& BLR & $33,9 \pm 10$ & $24,8 \pm 8,6$ & $25,8 \pm 8,8$ & 0,00 \\
Otur uzan & KT & $-1,8 \pm 8,0$ & $1,7 \pm 7,5$ & $2,2 \pm 7,6$ & 0,00 \\
testi & BLR & $-4,2 \pm 6,3$ & $0,6 \pm 6,0$ & $0,05 \pm 6,4$ & 0,00
\end{tabular}

*=friedman testi, $\mathrm{KT}=$ Kinesiotape, $\mathrm{BLR}=$ Bent Leg Raise 
Tablo-3: Grup içi ve gruplar arası aktif diz ekstensiyon derecesi ve otur uzan testi değerlerinin farklarının karşılaştırılması.

$\begin{array}{cccc}\text { Grup } & \Delta 30 \text { dakika- } & \Delta 24 \text { saat- Uyg. } & \Delta 24 \text { saat- } 30 \\ & \text { Uyg. Öncesi } & \text { Öncesi } & \text { dakika }\end{array}$

\begin{tabular}{ccccc}
\hline $\begin{array}{c}\text { Aktif diz } \\
\text { ekstensiyon }\end{array}$ & $\mathbf{K T}$ & $5,0 \pm 4,3$ & $6,2 \pm 4,2$ & $1,2 \pm 4,9$ \\
derecesi & $\mathbf{p}^{*}$ &, 000 &, 000 &, 198 \\
& $\mathbf{B L R}$ & $9,1 \pm 3,6$ & $8,1 \pm 3,9$ & $-1,0 \pm 3,9$ \\
& $\mathbf{p}^{*}$ &, 000 &, 000 &, 258 \\
\cline { 2 - 5 } & $\mathbf{p}^{* *}$ &, 000 &, 055 &, 104 \\
\hline Otur uzan testi & $\mathbf{K T}$ & $3,6 \pm 2,4$ & $4,1 \pm 2,6$ & $0,5 \pm 1,9$ \\
& $\mathbf{p}$ &, 000 &, 000 &, 171 \\
& $\mathbf{B L R}$ & $4,9 \pm 2,2$ & $4,3 \pm 2,8$ & $-0,6 \pm 2,4$ \\
& $\mathbf{p}^{*}$ &, 000 &, 000 &, 191 \\
\cline { 2 - 5 } & $\mathbf{p}^{* *}$ &, 010 &, 924 &, 032 \\
\hline
\end{tabular}

$*=$ Wilcoxon testi, $* *=$ Mann-Whitney $\mathrm{U}$ testi, $\mathrm{KT}=$ Kinesiotape, BLR= Bent Leg Raise, $\Delta=$ Fark değeri 